\title{
Size and settling velocity of suspended flocs during a Phaeocystis bloom in the tidally stirred Irish Sea, NW European shelf
}

\author{
C. F. Jago ${ }^{1, *}$, G. M. Kennaway ${ }^{2}$, G. Novarino ${ }^{2}$, S. E. Jones ${ }^{1}$ \\ ${ }^{1}$ School of Ocean Sciences, University of Wales Bangor, Marine Science Laboratories, Menai Bridge, Anglesey LL59 5AB, UK \\ ${ }^{2}$ Departrment of Zoology, The Natural History Museum, Cromwell Road, London SW7 5BD, UK
}

\begin{abstract}
The settling and resuspension of carbon-rich suspended particulate matter (SPM) are important determinants of pelagic and benthic productivity, and the fate of primary production, in tidally stirred shelf seas. The physical and biological properties of SPM were measured over $5 \mathrm{wk}$ of a declining spring plankton bloom, dominated by the flagellate Phaeocystis, in stratified and mixed waters of the Irish Sea, NW European shelf. SPM consisted of slow-settling, small flocs with a modal settling velocity of $2 \times 10^{-3}$ to $4 \times 10^{-3} \mathrm{~mm} \mathrm{~s}^{-1}$ in long-term suspension and fast-settling, large flocs with a modal settling velocity of $2 \times 10^{-2}$ to $2 \mathrm{~mm} \mathrm{~s}^{-1}$, deposited as benthic fluff at slack waters and resuspended by tidal currents; flocs reached $500 \mu \mathrm{m}$ in diameter and settled at up to $20 \mathrm{~mm} \mathrm{~s}^{-1}$. Larger flocs were composed of living Phaeocystis and other scavenged material. Floc size and settling velocity of SPM scaled on the weight percentage in SPM of arabinose, a photosynthate produced by Phaeocystis. Over a 5-fold range of arabinose content, there was a 3 order of magnitude range of median settling velocity. Larger flocs in mixed waters, with high Phaeocystis content, were stronger than smaller flocs in stratified waters with low Phaeocystis content. Resuspended flocs in mixed waters were stronger than flocs in long-term suspension. SPM concentration in mixed waters halved during the period of observation, with most of this reduction occurring in Week 1 . We conclude there was net sedimentation of Phaeocystis-enriched SPM as benthic fluff despite frequent resuspension.
\end{abstract}

KEY WORDS: SPM $\cdot$ Phytoplankton $\cdot$ Phaeocystis $\cdot$ Flocs $\cdot$ Settling velocity $\cdot$ Shelf seas

\section{INTRODUCTION}

Photosynthetic production by phytoplankton and subsequent sedimentation of phytodetritus is a major pathway for the transfer of mass and energy from the water column to the seabed. The consequent organic carbon flux is important with regard to the fate of associated biogeochemical components in the marine environment. The fate of carbon generated by phytoplankton depends on whether blooms act as retention or flux systems (Riebesell et al. 1995), i.e. whether energy and nutrients fixed during blooms are recycled in the water column, exported to higher trophic levels, or transferred to the seabed. Shelf seas account for 20 to $50 \%$ of marine primary production (Thomas et al. 2004), and sedimentation of particulate organic carbon probably accounts for about a half of net primary production in stratified parts of UK shelf seas. The rate at which such sedimentation occurs is important, since it governs biogeochemical and ecological impacts in the water column and at the seabed: it influences pelagic and benthic production by, respectively, reducing turbidity and creating a benthic fluff layer. Light attenuation due to turbidity reduces algal growth rate (Tett et al. 1993), while organic enrichment in the fluff layer produces seabed anoxia, even in areas of frequent resuspension (Jago et al. 1993). Shifts in the fate of suspended matter between export to the pelagic food web or deposition to the benthos are critical in the assessment of eutrophication. 
A key factor is the settling flux of phytodetritus in the form of aggregated material (flocs) typically composed of organic polymers, phytoplankton, heterotrophs, bacteria, faecal material and mineral matter. Flocs, which comprise most of the mass of suspended particulate matter (SPM), can grow to a large size, with a high surface area to volume ratio, high water content and low density. Much of the settling flux of SPM may be accounted for by large flocs, but flocs are easily broken by turbulence into primary components much smaller than the flocs themselves. Floc size varies on short time scales in the turbulent regimes of strongly tidal shelf seas (Jago et al. 2006), due to particle aggregation at slack water and disaggregation during tidal flow and to sedimentation at slack water and resuspension during tidal flow.

It is well known that SPM aggregation is associated with plankton blooms and, moreover, that phytoplankton mediate in SPM aggregation in the open ocean (e.g. Lampitt et al. 1993, Passow \& Alldridge 1994) and coastal waters (e.g. Eisma \& Li 1993). There are potential ecological impacts of particle aggregation associated with blooms, e.g. termination of bloom, algal species succession and availability of food to grazers. Aggregation requires cohesive particles to collide, the probability of which increases in high-concentration blooms (Riebesell 1991a). Known, or suspected, aggregation mechanisms involve bacteria (Biddanda \& Pomeroy 1988, Lochte \& Turley 1988, Passow \& Alldredge 1994) and extracellular polysaccharides secreted by algae as transparent exopolymer particles (TEP) (Smetacek 1985, Riebesell 1991b, Passow et al. 2001). The nutrient status of plankton cells probably affects their stickiness (Kiørboe et al. 1990), and enhanced aggregation has been attributed to an increase in stickiness due to nutrient depletion. The properties of the mucilaginous floc matrix depend on the species of secreting alga and this determines the structure of flocs and their microbial assemblages (Leppard 1995). So the shape, size and composition of flocs are diverse (Lampitt et al. 1993).

Gustafsson \& Gschwend (1997) have identified a functional separation of suspended and sinking particles in oceanic waters, but in dynamic tidal shelf seas, where aggregation, disaggregation, resuspension and sinking are quasi-continuous processes (Jago et al. 2006), the same material can be exchanged between a short-term resuspension population and a long-term suspension population as floc size changes on short time scales (i.e. shorter than a tidal cycle). So sinking and suspended particle populations are dynamic entities in that material is continuously transformed and exchanged between them. This is an important distinction between SPM behaviour in a tidally stirred shelf sea and in oceanic (or less energetic shelf) regions.
Note that, in the present paper, the term SPM will be used to describe any material that is part of the pelagic regime, whether sinking or not, even on a tidal time scale.

For settling flux and fate of SPM, the key floc property is settling velocity, which depends on floc size and floc density. Floc strength is also important because it determines how readily flocs are broken up, so it influences floc size. Floc size, density and strength are governed by both hydrodynamics (the turbulence regime that alternately creates and ruptures flocs according to its intensity) and biology (the microbiota secretions that bind particles together).

It is likely that a wide variety of combinations of turbulence regimes and microbiota assemblages will generate flocs with a wide spectrum of floc strength, floc density and hydrodynamic properties. In a tide-stirred shelf sea such as the NW European shelf, these properties are likely to show temporal variations on tidal, lunar and seasonal time scales and to show spatial differences between mixed and stratified regions.

Quantitative measurement of the critical properties (size, settling velocity) of the flocs that comprise SPM, and hence drive the impacts, is problematic in highenergy shelf seas where these properties change on short time scales. It is difficult to measure fragile flocs and their properties with sufficiently high resolution. Sediment traps, fine for open ocean or protected environments such as fjords, generally provide data on inappropriate time scales, and have dubious validity, in regions of strong tidal currents, and in situ cameras are difficult to utilise in strong tidal currents.

In the present paper, we provide quantitative data on floc size and settling velocity during the progress of a phytoplankton bloom using quasi in situ measurements. We report on $5 \mathrm{wk}$ of observations from the Irish Sea, NW European shelf, during a late spring (April/ May) bloom, that include high-resolution measurement of SPM properties at dynamically contrasting sites. The plankton was dominated by the flagellate Phaeocystis sp., which is prolific in many shelf seas at the end of the spring diatom bloom (Lancelot et al. 1994). The fate of Phaeocystis blooms is unclear, and some of the evidence is contradictory (Riebesell 1993, Weiss et al. 1994, Riebesell et al. 1995, Osinga et al. 1996), but there has been experimental evidence (Passow \& Wassman 1994) that colonies, as they become senescent, form a locus for aggregation and scavenge SPM and dissolved carbohydrates in the water column. We explore the hypothesis that this process is associated with rapid removal of SPM from the water column at the end of a bloom. We were unable to measure nutrients during the experiment. Moreover, the bloom was well advanced by the start of the experiment so we did not monitor the onset and development of the 
bloom. Consequently, this paper is concerned only with the behaviour of phytodetritus as the bloom declined.

\section{MATERIALS AND METHODS}

Study area. Observations were made in the Irish Sea at 4 sites (Fig. 1), with water depths from 18 to $90 \mathrm{~m}$, which encompassed water columns that were thermally stratified (western Irish Sea gyre, 90 m depth), mixed with periodic buoyancy stratification (Liverpool Bay, $22 \mathrm{~m}$ ), mixed (Red Wharf Bay, $18 \mathrm{~m}$ ) and frontal (on the stratified side of the western Irish Sea tidal mixing front, $80 \mathrm{~m})$. The sites were occupied over tidal cycles (25 to $37.5 \mathrm{~h}$ ), weekly during a $5 \mathrm{wk}$ observation period in April/May.

Physical measurements. Particle size and settling velocity of SPM were measured in near-surface, middepth and near-bed waters. Particle size spectra were measured with an onboard Galai-Cis 100 laser sizer on samples collected from GoFlo bottles on the ship's CTD using a non-destructive technique to preserve floc integrity (Jago \& Bull 2000); this employs an inner plas-

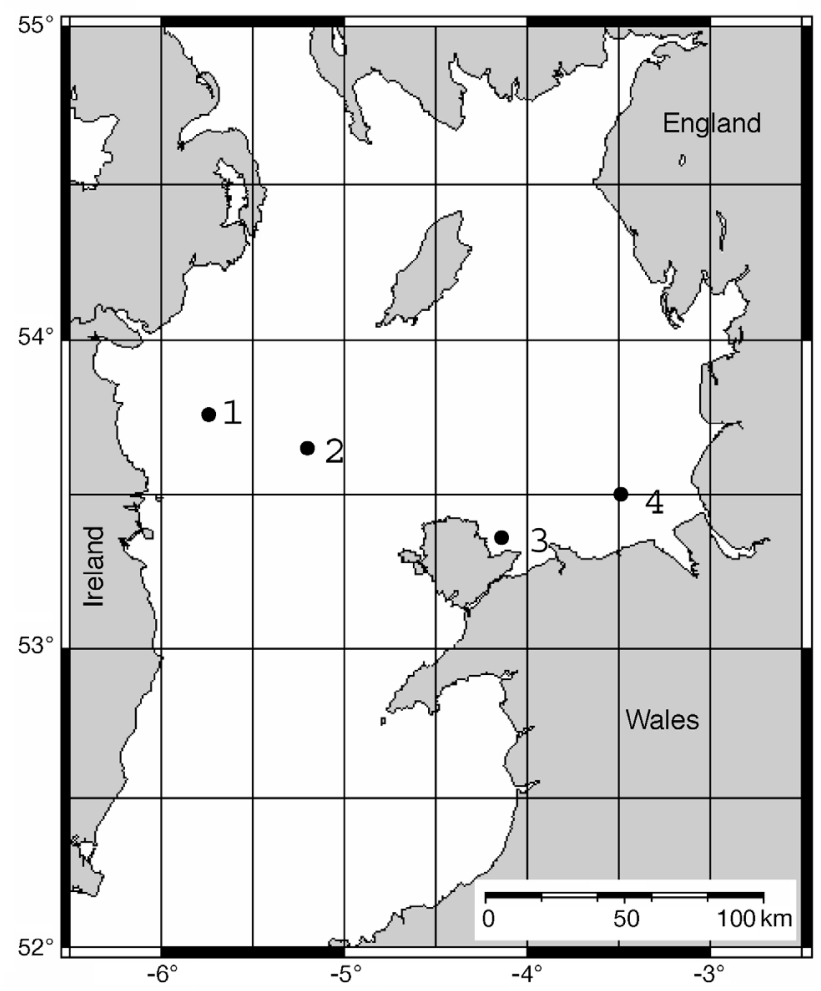

Fig. 1. Sampling stations - 1: western Irish Sea gyre (thermally stratified); 2: Irish Sea front (thermally stratified); 3: Red Wharf Bay (mixed); 4: Liverpool Bay (mixed but periodically buoyancy stratified) tic container (sleeve) for the GoFlo bottles of the ship's CTD; the sleeve is inserted into the full bottle after its recovery, the bottle is gently inverted and the sleeve, with an 'undisturbed' sample, then withdrawn; the sample is then transferred directly to the laser sizer without having passed through any taps. The laser sizer measures particles up to $600 \mu \mathrm{m}$ and has a video microscope that allows direct visualisation of SPM. The efficacy of the sampling routine and the degree to which samples were 'undisturbed' were tested in a pilot study elsewhere by comparing size spectra produced by the Galai-Cis with in situ spectra provided by a Lasentec particle sizer (Law et al. 1997). The sampled and in situ spectra were very comparable from which it was deduced that the sampling routine was not significantly disrupting flocs. However, the Lasentec is suitable only for relatively high SPM concentrations and so could not be deployed in the Irish Sea experiment where SPM concentrations were too low.

Quasi in situ settling velocity spectra were measured using large volume settling velocity tubes (SVTs; previously described by Jones \& Jago 1996). The SVT is essentially a larger volume (5 l) Owen's tube that is triggered at the required depth with the tube horizontal, then is switched to the vertical on recovery and used as a settling tube. Ten aliquots are collected by bottom withdrawal at designated intervals (from $30 \mathrm{~s}$ to $7 \mathrm{~h}$ ), and their SPM content is determined by gravimetry. SVTs provide settling velocity spectra even in lowconcentration shelf waters (SPM mass concentrations were typically $<10 \mathrm{mg} \mathrm{l}^{-1}$ ) because of their large volume (relative to the conventional Owen's tube that is routinely deployed in turbid estuarine waters). The SVT improves on an Owen's tube by means of its closure mechanism: on triggering, the horizontal tube slides laterally to capture the water sample, thus reducing the shock wave that normally results when conventional Owen's tubes are closed. The original SVTs (Jones \& Jago 1996) were modified for the Irish Sea deployments by slowing the rate of closure; flume tests using dyes showed that turbulence was dramatically reduced with the slower closure rate. The ship was not anchored during collection of tidal time series so as to minimise sampling-induced turbulence. We are therefore confident that the SVTs were collecting undisturbed samples of flocs. An additional potential drawback with settling tubes of any kind is that additional aggregation occurs within the tube after recovery. Most of our samples were returned to the ship, and orientated at an upright position, in $<2$ min of closure, so settlement of particles onto the tube walls was usually slight; nevertheless, on recovery, tubes were gently rotated before being uprighted so as to counteract this tendency. Visual observation convinced us that within-tube modification of flocs was minimal under 
the low-concentration conditions that we encountered. Note that, while near-bed samples from the CTD for particle sizing were never closer to the seabed than 2 mab (metres above bed), the near-bed SVTs were fired at 1 mab.

Please note that in this paper 'settling velocity' is used as an inherent physical property of the suspended particles (the property used in shelf hydrodynamic models); hence, it is measured in stationary, non-turbulent water. 'Sinking rate' is the parameter determined when particles are caught in sediment traps, i.e. when they sink through naturally turbulent waters. However, to a first approximation, in highly turbulent waters where there is an equal chance that turbulence will carry particles upwards and downwards, the 2 terms should be synonymous.

Mass concentration of SPM was determined using profiling, $0.2 \mathrm{~m}$ path length, beam transmissometers attached to the CTD, calibrated in situ by conventional gravimetry (see Jago \& Jones 1998). Calibrations of concentration with optical transmittance were uniformly significant $\left(\mathrm{r}^{2}=0.74, \mathrm{p}<0.01, \mathrm{n}=300\right.$ for the complete dataset).

Biological measurements. Microalgal functional groups and species, as well as floc structures, were identified using scanning electron microscopy (SEM) on filtered samples. For higher resolution, in situ information, microalgal activity was observed using proxies: as concentrations of a suite of monosaccharides (arabinose, fucose, fructose, galactose, glucosamine, glucose, mannose, rhamnose, ribose) that occur in photosynthate, using high $\mathrm{pH}$ anion exchange chromatography with pulsed amperometric detection on filtered samples (Kerherve et al. 1995) and as conventional fluorescence-derived chlorophyll a concentration (using a profiling fluorometer calibrated with filtered samples, $\mathrm{r}^{2}=0.55, \mathrm{p}<0.01, \mathrm{n}=295$ for the complete dataset).

The SVTs were also used to determine the effective settling velocity of chlorophyll a by determining the chlorophyll content of the aliquots withdrawn from the tubes during the settling period. These data were used to generate chlorophyll settling velocity spectra in the same way as the SPM settling velocity spectra. This information provided insight into how chlorophyll was distributed through the particle spectra.

Measurement strategy. SPM concentration, particle size and chlorophyll a were measured hourly over tidal cycles (concurrently with vertical profiles of ADCPderived velocity, salinity and temperature) at 3 depths (near-surface, mid-water, near-bottom). Settling velocity was measured at the surface and $1 \mathrm{mab}$ with lower temporal resolution (at peak flows and slack waters) because of the time needed for each settling experiment. Monosaccharides were determined in a subset of the samples. SEM identification of plankton was carried out on a few randomly chosen samples during each measurement period.

\section{RESULTS}

\section{Phytoplankton and SPM properties}

\section{Phytoplankton characteristics}

Microalgae at the coastal sites and in the chlorophyll maximum in the gyre were similar, being dominated by small flagellates (individual cells of 5 to $10 \mu \mathrm{m}$ ) including Phaeocystis monads (with chitin exofilaments) and 2 dinoflagellates (Gyrodinium sp. 1 and sp. 2), as well as unidentified yeast cells. Chlorophyll a levels, marginally greater in the coastal waters than in the thermocline of the gyre, indicated that the Phaeocystis bloom was already in decline at the start of the sampling period. Average chlorophyll a concentrations progressively declined during the period of observations from 2.2 to $1.2 \mu \mathrm{g} \mathrm{l}^{-1}$ (Table 1).

The suite of monosaccharides was similar at all sites. Glucose was usually the most abundant monosaccharide though its relative contribution varied (10 to $60 \%$ ). At the stratified gyre site, the other primary monosaccharides were rhamnose, galactose, xylose/mannose and ribose in the bottom mixed layer (BML), while galactose, xylose/mannose and arabinose characterised the subsurface chlorophyll maximum. At the coastal sites, arabinose was more dominant, compris-

Table 1. Tide-averaged parameters for Weeks 1 to 5 at the coastal sites (Stations 3 and 4). SPM: suspended particulate matter

\begin{tabular}{|llccccc|}
\hline $\begin{array}{l}\text { Week no./ } \\
\text { days from } \\
\text { start }\end{array}$ & $\begin{array}{c}\text { Tidal } \\
\text { range } \\
(\text { coastal, } \mathrm{m})\end{array}$ & $\begin{array}{c}\text { Mean chlorophyll } \\
\text { concentration } \\
\left(\mu \mathrm{g} \mathrm{l}^{-1}\right)\end{array}$ & $\begin{array}{c}\text { Mean median } \\
\text { particle size } \\
(\mu \mathrm{m})\end{array}$ & $\begin{array}{c}\text { Mean SPM } \\
\text { concentration } \\
\left(\mathrm{mg} \mathrm{l}^{-1}\right)\end{array}$ & $\begin{array}{c}\text { Slack water } \\
\text { surface SPM } \\
\text { concentration }\left(\mathrm{mg} \mathrm{l}^{-1}\right)\end{array}$ & $\begin{array}{c}\text { Mean arabinose/ } \\
\text { SPM ratio } \\
\text { by weight }\end{array}$ \\
\hline $1 / 1$ & 3.0 neap & 2.2 & 118 & 8.5 & 5.0 & 0.32 \\
$2 / 8$ & 5.2 spring & 1.5 & 200 & 10.5 & 5.5 & 0.43 \\
$3 / 13$ & 2.5 neap & 1.8 & 96 & 3.6 & 2.8 & 0.21 \\
$4 / 21$ & 4.3 spring & 1.6 & 89 & 5.6 & 2.5 & 0.19 \\
$5 / 29$ & 3.1 neap & 1.2 & 69 & 4.4 & & 0.17 \\
\hline
\end{tabular}


ing about $33 \%$ of total monosaccharides. These associations are comparable to those reported during blooms in the North Sea (Janse et al. 1996).

\section{SPM properties}

SPM concentrations were everywhere low $(<10 \mathrm{mg}$ $\mathrm{l}^{-1}$ ) and diminished during the period of observation (Table 1). The lowest concentrations were in the surface mixed layer (SML) of the stratified zone, while the highest concentrations were near the bed in the BML of the stratified zone. SEM imagery of filtered samples, and laser sizing and video microscopy of unfiltered samples, showed that SPM comprised flocs ranging from microflocs $<50 \mu \mathrm{m}$ to macroflocs $>500 \mu \mathrm{m}$. Video microscope images on the Galai Cis laser sizer showed that the larger flocs were constructed predominantly from Phaeocystis colonies with copious, attached fragments of inorganic and dead organic matter.

SPM in the SML of the stratified gyre was characterised by crustose flocs (largest size $100 \mu \mathrm{m}$, typical median size $20 \mu \mathrm{m}$ ) with bacteria and mucilage strands. SPM in the BML of the gyre was dominated by inorganic detritus held together by biological components in small flocs (rarely exceeding $50 \mu \mathrm{m}$, typical median size $30 \mu \mathrm{m}$, except on spring tides when ambient median size typically increased to ca. $45 \mu \mathrm{m}$ and to ca. $200 \mu \mathrm{m}$ at peak flows). The few microalgae present-Phaeocystis monads and non-motile cells with some gymnodinoid dinoflagellates-were generally associated with flocs.

At the coastal sites, SPM was dominated by flocs, comprising Phaeocystis (monads with filaments and mucilage), small, centric diatoms with a few nonaggregated uni- and bi-flagellates, dead organic and inorganic matter. Flocs in coastal surface waters ranged up to $400 \mu \mathrm{m}$ with time-varying median size typically 50 to $150 \mu \mathrm{m}$, while near-bed flocs were usually larger, some exceeding $500 \mu \mathrm{m}$, with time-varying median size usually 50 to $250 \mu \mathrm{m}$ and maximum median size $460 \mu \mathrm{m}$. Tidal variations of SPM size were due to tidal resuspension, with coarser particles at times of resuspension.

The particle size of SPM was therefore very variable: significantly smaller at the stratified site (median size of individual samples as low as $10 \mu \mathrm{m}$ ) than at the coastal sites (median size sometimes exceeding $400 \mu \mathrm{m}$ ). Hence, there were higher concentrations, but much smaller particles, near the bed in the stratified waters than in the coastal waters. At the coastal sites, particle size diminished during the period of observation (Table 1).

Median settling velocities of SPM varied from ca. $4 \times$ $10^{-4}$ to ca. $2 \times 10^{-1} \mathrm{~mm} \mathrm{~s}^{-1}$. The fastest settling velocities were at the coastal sites, the slowest in the strati-

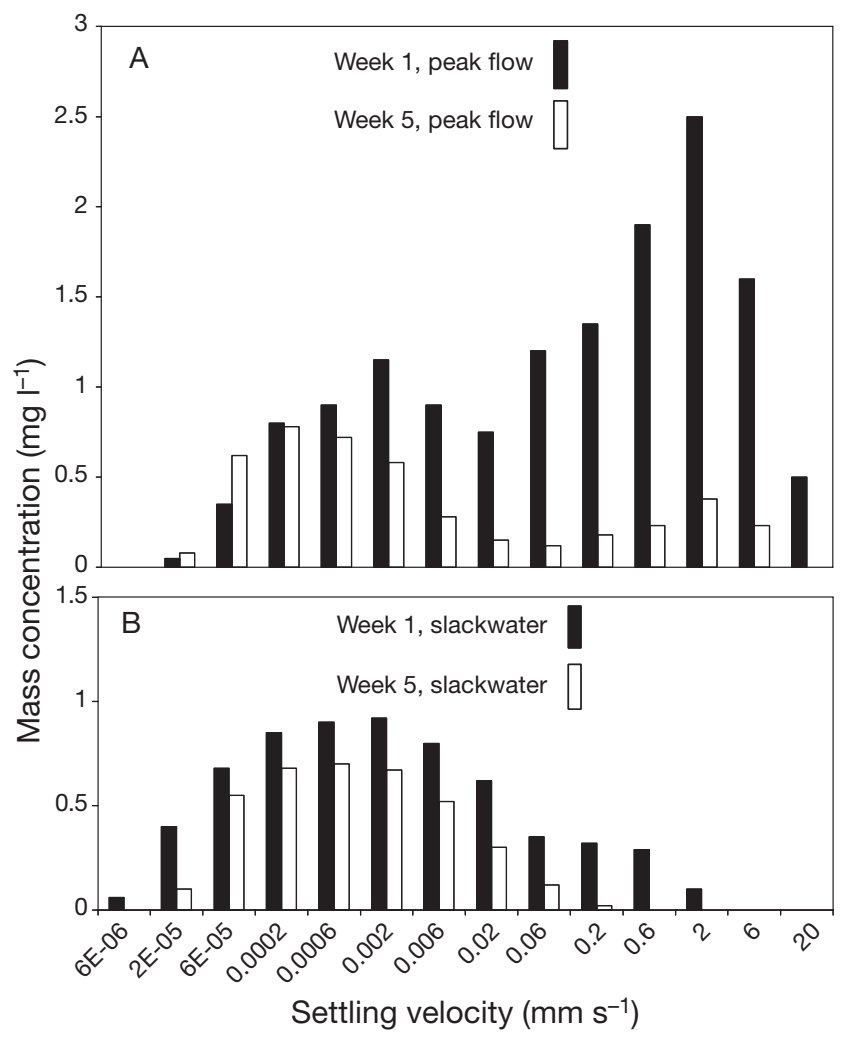

Fig. 2. Typical settling velocity spectra, 1 mab at the coastal site showing settling velocities at peak flow (A) and slack water (B). A slow-settling suspension component is present at all times, and a fast-settling resuspension component is present only at peak flow. The figure shows modification of the settling velocity spectra between Weeks 1 (black) and 5 (white) of the study period

fied gyre. Our median values are smaller than many previously reported settling velocities in coastal and estuarine waters because the SVT determination includes the small, slowly settling particles which many studies, using video cameras, have ignored. An averaged value of settling velocity is not particularly useful, as many settling velocity spectra were bimodal: a slow-settling mode $\left(0.002\right.$ to $\left.0.004 \mathrm{~mm} \mathrm{~s}^{-1}\right)$ in longterm suspension and a fast-settling mode ( 0.02 to $2 \mathrm{~mm}$ $\mathrm{s}^{-1}$ ) subject to short-term resuspension (e.g. Fig. 2). The average settling velocity of Phaeocystis cells in a microcosm has been reported as ca. $0.016 \mathrm{~mm} \mathrm{~s}^{-1}$ (Osinga et al. 1996); our fast-settling mode was up to 2 orders of magnitude faster (because our flocs were not Phyaeocystis alone).

Settling velocities of chlorophyll were consistently greater than for SPM, except in the stratified gyre. For the coastal stations, median chlorophyll settling velocity was about 2.5 and 1.5 times the median SPM settling velocity in surface and bottom waters, respectively. Chlorophyll was therefore concentrated in the faster settling fractions of SPM. 


\section{Variations over tidal cycles}

Coastal sites

Spring tide currents reached $0.82 \mathrm{~m} \mathrm{~s}^{-1}$ at the surface (Fig. 3A). There were strong $\mathrm{M}_{4}$ signals $\left(\mathrm{M}_{4}=\right.$ frictional quarter-diurnal tidal component) in SPM concentration throughout the water column: concentration max-
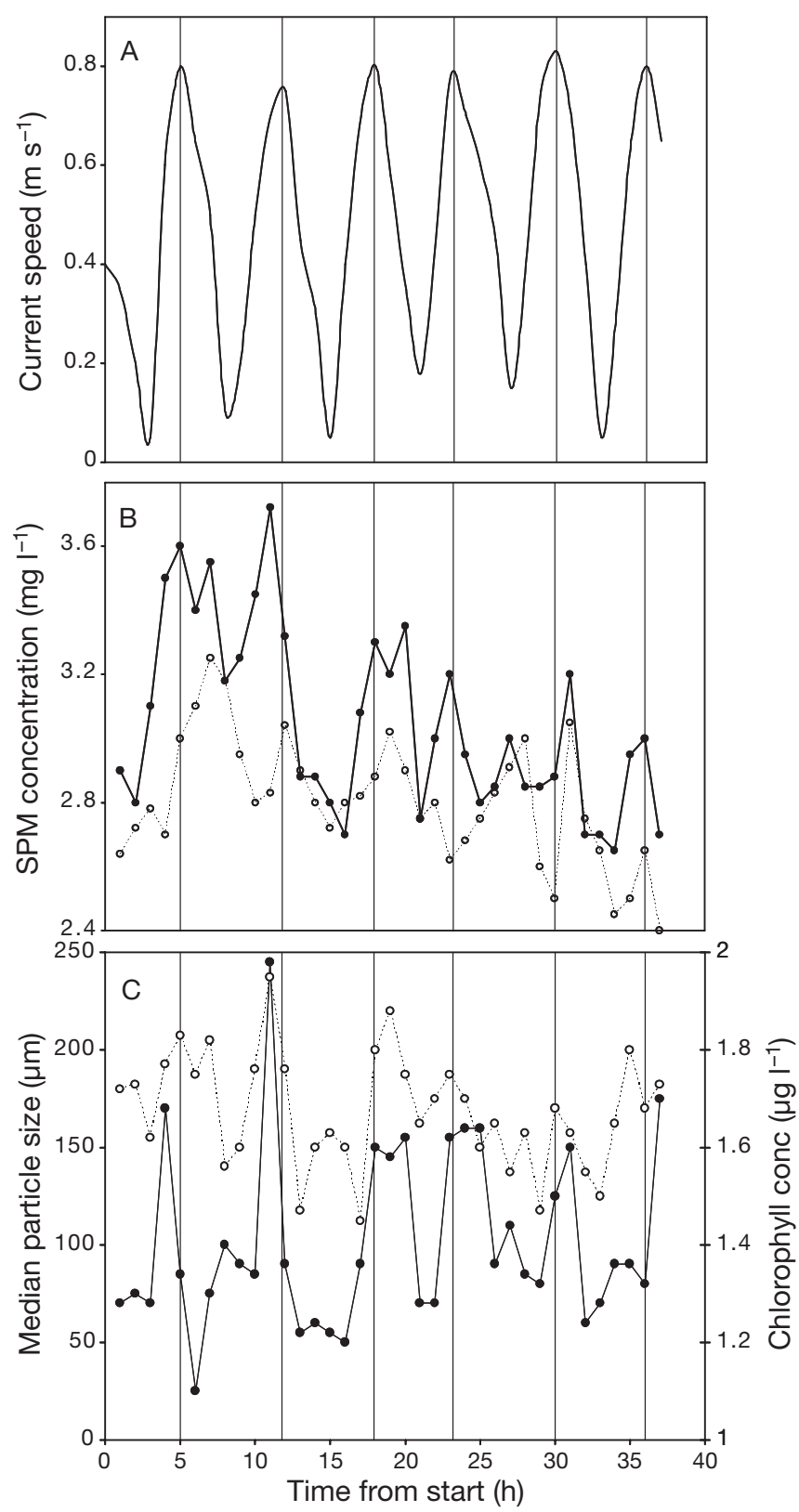

Fig. 3. Time series over tidal cycles at Station 4: (A) depthaveraged current speed, (B) SPM mass concentration (near-bed; O...... O: near-surface) and (C) near-bed SPM median particle size $(-\bullet)$ and chlorophyll concentration $(\mathrm{O} \cdots . . . \mathrm{O})$. Vertical lines: times of peak flow ima coincided with velocity maxima near the bed, usually with phase lags that increased higher in the water column (Fig. 3B), indicative of resuspension. Particle size maxima coincided with concentration maxima (Fig. 3C), with comparable phase lags through the water column; resuspended particles were therefore larger. Variations of chlorophyll a concentration were less strongly periodic, though maximum concentrations occurred at, or close to, times of maximum velocity (Fig. 3C), because the resuspended matter included living algal material. Comparable, but more subdued, signals in all parameters occurred on neap tides. The Liverpool Bay site (Station 4) was periodically buoyancy stratified due to freshwater input from the Mersey estuary and tidal straining, which added complexity to the vertical profiles of SPM properties, but this interesting aspect is not pertinent to the primary thrust of this paper.

\section{Stratified site}

Spring tide currents reached $0.35 \mathrm{~m} \mathrm{~s}^{-1}$ at the surface in the thermally stratified gyre of the western Irish Sea (Fig. 4A); there was a $2^{\circ} \mathrm{C}$ temperature difference between the surface and bottom. There was marked decoupling of the surface and bottom mixed layers with respect to SPM (Fig. 4B). The SML showed strong $\mathrm{M}_{2}$ variation $\left(\mathrm{M}_{2}=\right.$ principal, semi-diurnal lunar tide) indicative of advection of a lateral concentration gradient. The BML showed $\mathrm{M}_{4}$ variation on spring tides (but none on neaps) when bottom concentration maxima were associated with velocity maxima, indicative of tidal resuspension, but usually preceding them by an hour or more. This has been previously interpreted (Jago et al. 1993, Jago \& Jones 1998) as diagnostic of resuspension of a limited reservoir of seabed material. This implies either that the fluff layer was thin or that the deeper layers of fluff were sufficiently cohesive to resist resuspension. Particle size maxima in the BML also preceded velocity maxima (Fig. 4C); this could be indicative of floc break-up at peak velocity, but as there was no indication of an increase in small particles, it is more likely a consequence of a limited supply of larger flocs for resuspension. Particle size showed no systematic variation in the SML. There was $\mathrm{M}_{2}$ variation in chlorophyll concentration in the upper and lower layers, indicative of tidal advection of chlorophyll patches; there was no evidence of chlorophyll resuspension (Fig. 4C), which suggests that the resuspended matter on spring tides did not contain living algal material.

We should emphasise that our 'near-bed' data relate to ca. 2 mab for most parameters (except settling velocity). At this height above bed it is clear that the resus- 
pended material was benthic fluff, not seabed sediment per se; our transmissometer time series showed that the resuspension threshold occurred at very low current velocities, often $<0.1 \mathrm{~m} \mathrm{~s}^{-1}$ (cf. Jago et al. 1993, 2002).

\section{Interrelationships of physical and biological properties of SPM}

Particle size showed minimal correlations with SPM mass concentration (Fig. 5A) and chlorophyll a concentration (Fig. 5B). The latter does not negate the possibility of a biological influence on floc size: chlorophyll has low temporal resolution as an indicator of algal activity (days), while floc aggregation and disaggregation have shorter time scales (hours or less). Moreover, chlorophyll $a$ is associated with all photosynthetic activity in the water column, but it can be a poor proxy
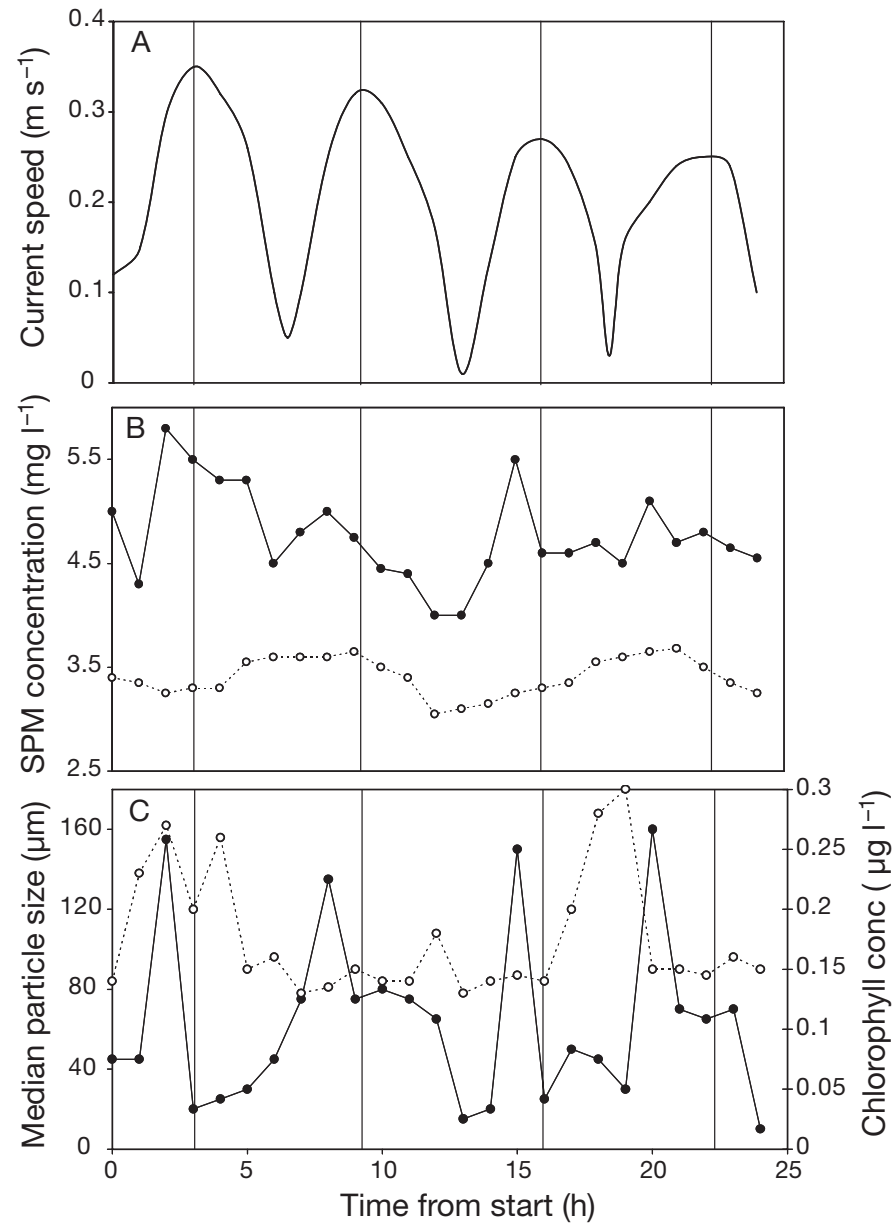

Fig. 4. Time series over spring tidal cycles at Station 1: (A) depth-averaged current speed, (B) SPM mass concentration (- - near-bed; O ….. O: near-surface) and (C) near-bed SPM median particle size $(\bullet-\bullet)$ and chlorophyll concentration $(\mathrm{O} \cdots . . . \mathrm{O})$. Vertical lines: times of peak flow for algal activity because this single measurement of chlorophyll does not provide information on the health of the algal assemblage: in a senescent bloom, biomass may be high, although chlorophyll a concentrations

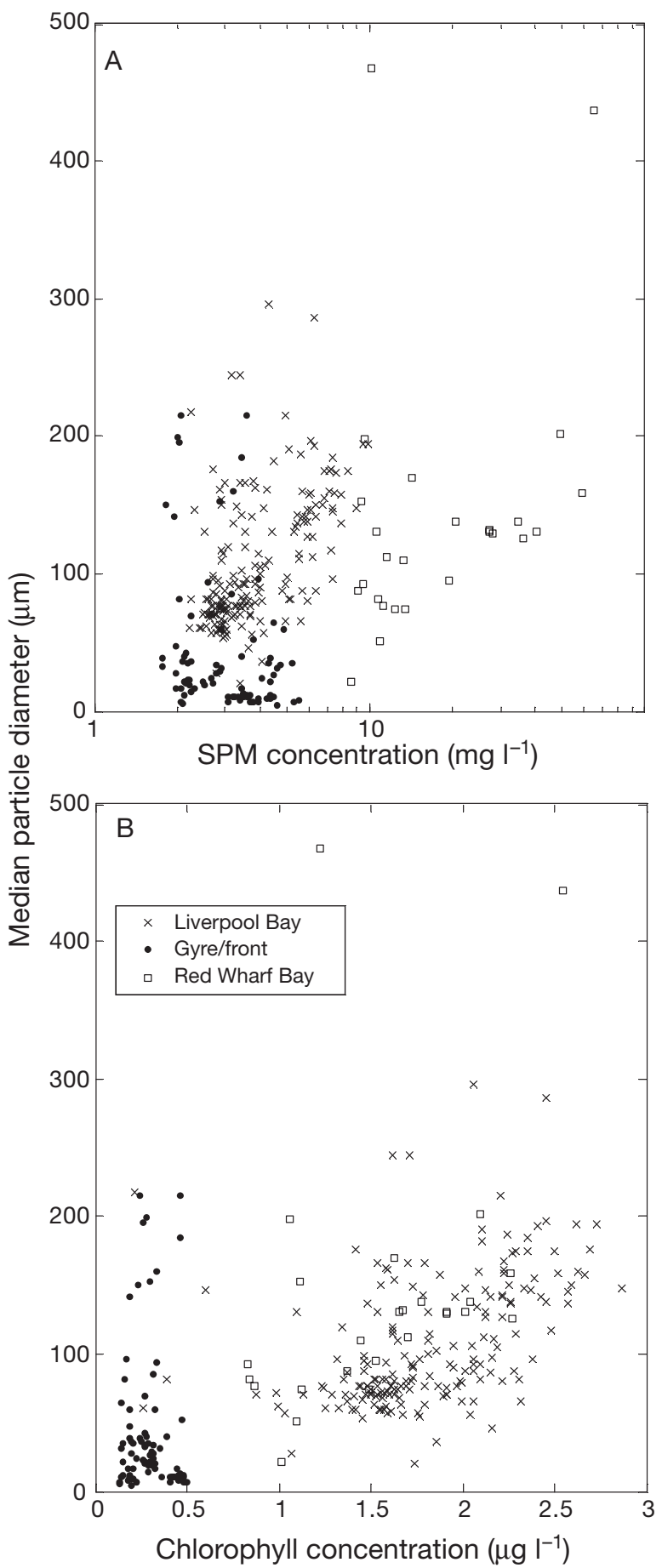

Fig. 5. Relationships between median particle size and (A) SPM concentration and (B) chlorophyll concentration at Stations 1 and 2 (gyre/front), at Station 3 (Red Wharf Bay) and at Station 4 (Liverpool Bay). Neither SPM nor chlorophyll concentrations can usefully be used to predict particle size 

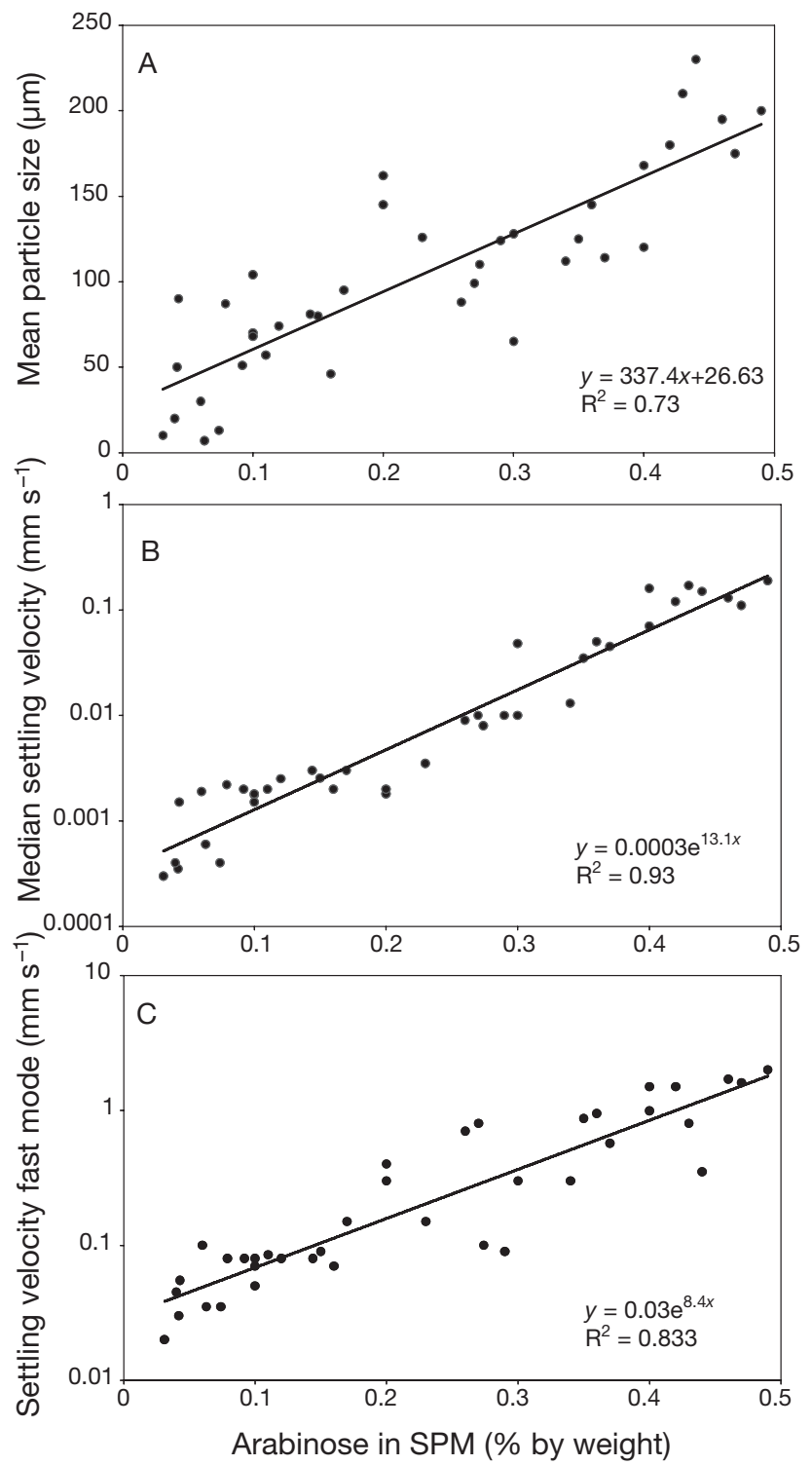

Fig. 6. Association of (A) mean particle size, (B) median settling velocity and $(C)$ settling velocity of fast mode, with arabinose content of SPM ( $\%$ by weight)

are low and the breakdown products of chlorophyll (phaeophorbides) are high.

Arabinose contribution to SPM, parameterised as the weight percentage of arabinose in SPM, showed a strong association with SPM mean particle size, i.e. large flocs were always rich in arabinose (Fig. 6A). This relationship derives from data from stratified and mixed waters and incorporates mean particle sizes from 20 to $230 \mu \mathrm{m}$. Arabinose is known to be a fingerprint for living Phaeocystis (Janse et al. 1996) and is effectively a proxy for Phaeocystis presence and photosynthetic activity. Its presence in SPM is diagnostic of living algal cells incorporated into the floc fabric (confirmed by our video microscope images). The largest flocs with the greatest content of living Phaeocystis were associated with resuspended benthic fluff at the coastal sites. Other monosaccharides failed to show a significant association with SPM properties. Glucose, which has been observed elsewhere as the primary constituent of floc matrices (Passow et al. 2001), was the most common monosaccharide, but it did not exhibit any relationship to SPM properties.

Arabinose, used here as a proxy for Phaeocystis photosynthesis, is unlikely to be the agent of aggregation. The most likely candidates are extracellular polysaccharides secreted by algae and/or bacteria in the form of TEPs, as discussed above. Our observations were made at a time of bloom decline, when nutrients were probably low and algae were possibly leaking sticky exopolymers (Smetacek 1985, Kiørboe et al. 1990).

Since settling flux is determined by settling velocity rather than particle size per se, it is more significant that we saw a strong association of arabinose contribution to SPM with median settling velocity (Fig. 6B). Note that arabinose associations with settling velocity and particle size were determined from samples recovered using different methods. Over the 5 -fold range of arabinose activity encountered during the observation period, we measured a 3 order of magnitude variation in median settling velocity from ca. $4 \times 10^{-4}$ to ca. $2 \times$ $10^{-1} \mathrm{~mm} \mathrm{~s}^{-1}$ (i.e. ca. 0.001 to ca. $0.7 \mathrm{~m} \mathrm{~h}^{-1}$ ). The smallest values were in stratified waters, the largest values in mixed waters. SPM with negligible Phaeocystis content was settling so slowly as to effectively be in long-term suspension, while SPM with high Phaeocystis content could settle fast enough to accumulate on the seabed during slack water periods. There was a strong association between the settling velocities of the fast-settling mode (the resuspension mode) of the bimodal settling velocity spectra and arabinose content (Fig. 6C). 'Sinking' particles (those periodically resuspended and settling) were Phaocystis-rich, while 'suspended' particles (those in long-term suspension) were Phaeocystis poor. The flocs in the most Phaeocystis-enriched SPM reached $20 \mathrm{~mm} \mathrm{~s}^{-1}\left(72 \mathrm{~m} \mathrm{~h}^{-1}\right)$. Sedimentation of such fast-settling flocs could potentially clear the entire water column over slack water periods at the coastal sites (and, by inference, most of the mixed eastern Irish Sea). So this material (still living) was being repeatedly sedimented and resuspended on a tidal time scale.

\section{DISCUSSION}

\section{Temporal variability of floc properties}

SPM characteristics varied over tidal cycles: larger flocs were resuspended by tidal currents at the coastal sites since increased mean particle sizes were ob- 
served at peak flows (and during the 1 period of intensive wave activity encountered during the study); the resuspended flocs had a high arabinose content, so they were still enriched in living Phaeocystis. Resuspended flocs were clearly strong enough to resist disaggregation by turbulence, since peak floc size corresponded to peak tidal velocity.

Superimposed on the tidal cycling of deposition and resuspension, there was a progressive change in SPM properties over the time scale of our observation period, most marked at the coastal sites. SPM concentration, median particle size and arabinose content were some $50 \%$ lower in Week 5 than in Week 1 (when the neap tide characteristics were very comparable; see Table 1). Tide-averaged SPM mass concentration declined (from 8.5 to $4.4 \mathrm{mg} \mathrm{l}^{-1}$ at the coastal sites), and slack water mass concentrations also fell, on average, by $50 \%$ during the $5 \mathrm{wk}$ period; thus, there was net sedimentation, and/or remineralisation, and/or advection away from the sites. These reductions effectively took place within the transition from spring to neap tides in Weeks 2 and 3. A comparable $50 \%$ loss of Phaeocystis biomass at the decline of a bloom under different conditions in a pelagic mesocosm was reported by Osinga et al. (1996).

A comparison of 1 mab settling velocity spectra at a coastal site illustrates the progression of SPM characteristics (Fig. 2). At slack waters and peak flows of comparable tides between Weeks 1 and 5, SPM concentration and median settling velocity were reduced. The concentration of the suspension component (the slow-settling mode) diminished despite its slow sinking rate; we surmise that this occurred because the smaller particles were scavenged by larger flocs (so transferring material from the suspension to the resuspension/sinking component); alternatively, the small particles advected away from the study sites. The concentration of the resuspension component (the fastsettling mode) also diminished. Between Weeks 1 and 5 , the contribution of the resuspension component to total SPM mass at 1 mab at Site 4 decreased from ca. 53 to ca. $16 \%$. So a growing proportion of it was permanently sedimented to the seabed, and/or it was remineralised (the latter would be accelerated by frequent resuspension events), and/or it advected away due to residual currents. Residual flows in the Irish Sea, driven by wind, mean tide and density gradients, are very variable, but are generally an order of magnitude less than tidal stream flows. Given that the greatest reduction occurred during 1 spring to neap period, i.e. a period of diminishing tidal energy, the most likely explanation is net sedimentation to the bed as a fluff layer. The inference is that the larger flocs showed net 'sinking', and therefore a loss to the water column, over the study period despite being regularly resus- pended. This suggests that the fluff layer became more cohesive, and thus more resistant to resuspension, over time, and/or it was incorporated into the bed.

A comparable phenomenon-net loss of SPM from the water column despite recurrent resuspensionwas reported from the southern North Sea by Jones et al. (1998), and new observations from the southern North Sea show that turbidity reduces dramatically at the end of the spring bloom (D. Mills pers. comm.); this suggests that our observation is not a localised phenomenon.

There are few data on organic matter in the seabed sediments at our observation sites, though Gowen et al. (2000), with very limited data, report no increase in organic matter in the seabed sediments of Liverpool Bay from bloom fall-out. However, the immediate result of net sedimentation of phytodetritus is a benthic fluff layer rather than augmentation of the bulk organic content of the seabed sediment. Sedimentation of phytodetritus will cause the fluff layer to thicken without it necessarily being incorporated into the surficial sediment. The fluff layer is not likely to be sampled by conventional grabs or box corers (it is wafted away as the grab hits the bed) so its contribution to the organic loading of the bed may be undetected.

The ecological impacts of a rapid settling flux of phytodetritus are likely to be profound: a significant decrease in light attenuation that allows Phaeocystis to survive even when sedimented to the seabed (cf. Jones et al. 1998), as well as changes to the benthic biogeochemical regime and exchanges due to temporary benthic anoxia - even thin fluff accumulation on clean sandy beds with low bulk organic matter content can generate temporary anoxia (cf. Jago et al. 1993). Furthermore, the fluff layer persists on the bed for months after its initial sedimentation (Jago \& Jones 1998).

\section{Spatial variability of floc properties}

Our values show a large spatial variability within the Irish Sea, principally between stratified and mixed waters. There was a marked contrast between slowsettling, small flocs with low Phaeocystis content in the stratified zone and fast-settling, large flocs with high Phaeocystis content in the mixed zone. Resuspension and sedimentation occurred in both zones, but flocs remained smaller in the BML of the stratified zone. SPM concentrations were greater near the bed of the BML of the stratified zone than near the bed in the mixed zone.

Hence, in the BML of the stratified zone, we observed higher concentrations of small, slow-settling flocs; slow settling velocities reduced the amount of sedimentation at slack waters. The resuspendable fluff 
layer seems to have been limited in that it was quickly depleted during resuspension events, either because the fluff layer was indeed thin or because its deeper layers were sufficiently cohesive to resist resuspension having consolidated during previous neap tides. We deduce that floc exchange between water column and bed in the stratified zone was limited and much of the SPM remained suspended. By contrast, in the mixed zone, we observed lower concentrations of large, fastsettling flocs; there was no evidence of any limitation on fluff availability for resuspension and there was clearly considerable floc exchange between water column and bed.

Our results show that there are no single values of mean floc size and settling velocity that could be applied to all parts of the Irish Sea.

Values of floc properties in less dynamic areas are not comparable to a tide-stirred sea like the Irish Sea. Our fastest sinking flocs had settling velocities on an order of magnitude faster than previously reported SPM settling velocities in nearshore zones and estuaries, which cluster around $2 \mathrm{~mm} \mathrm{~s}^{-1}$ (see Hill 1998 for discussion). Published values of settling velocities of flocs with a high biological component in coastal/continental margin environments cover a range of 0.01 to $1.74 \mathrm{~mm} \mathrm{~s}^{-1}$ (e.g. Hansen et al. 1996, Diercks \& Asper 1997, Pilskaln et al. 1998, Shanks 2002). None of these are from environments that are as dynamic as our tidestirred coastal sites (and most are in deeper water), and all are significantly smaller than the largest values of our fast-settling mode. Moreover, these published values themselves cover a wide range; it is clear that floc settling velocity is geographically and spatially very variable.

Resuspension is probably an important contributory factor here. Sedimented flocs are undoubtedly modified while on the seabed; it is likely that some consolidation of material occurs in the short time intervals between deposition and resuspension, so that resuspended flocs are larger than when previously deposited. Flocs subjected to frequent sedimentation and resuspension are likely to differ from flocs that are in long-term suspension.

\section{Strength of shelf sea flocs and marine snow}

An interesting question is whether our observed flocs had comparable properties to the flocs that constitute oceanic marine snow. We did not make any measurements of floc strength. However, the relationship between settling velocity $s_{\mathrm{V}}$ and particle size $D$ is of the form $S_{\mathrm{v}}=D^{n} ; n$ varies in response to, and can be used as an indicator of, floc strength-it has values of 2 for quartz particles in the Stokes regime, 1.2 for strong estuarine flocs and 0.4 for fragile marine snow in the open ocean (Winterwerp 1998). Using our complete dataset, $n$ has a value of 1.1, where $s_{\mathrm{v}}$ and $D$ are modal values (Fig. 7A); we use modal values to increase comparability with studies that have considered only coarser particles (using video techniques). Closer examination of the relationship between $S_{\mathrm{v}}$ and $D$ shows that it depends on floc provenance; distinct differences exist between mixed and stratified sites (Fig. 7B). For smaller flocs in stratified waters, $n=0.5$, while for larger flocs in mixed waters, $n=1.3$ (Fig. 7B), with a transition at ca. $50 \mu \mathrm{m}$. This implies that floc strength increased with size. This seems counter-intuitive since larger, fluffy flocs should be weaker than the smaller, compact flocs from which they have formed. However, the smaller, weak flocs were from stratified waters with low turbulence and low arabinose, i.e. weak flocs formed under low turbulent shear and in the absence of a living, algal component. Larger, strong flocs were from mixed waters with high turbulent shear and high arabinose: sufficient turbulence to create more forceful collisions and with the contained living algae probably producing a TEP glue to forge stronger flocs. It is noteworthy that our flocs in coastal waters were stronger than those previously observed from marine snow in the open ocean, while those from stratified waters

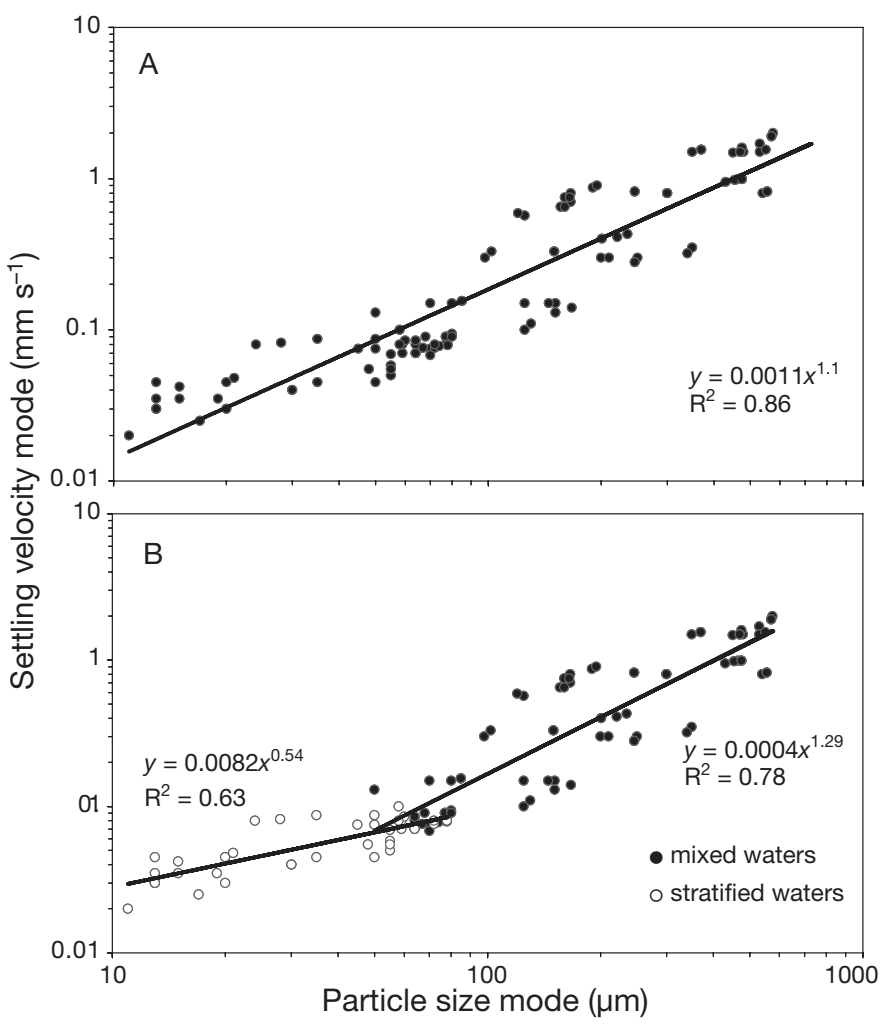

Fig. 7. Relationship of modal particle size and modal settling velocity for (A) all data and (B) dataset separated by provenance 
were much the same as marine snow. We conclude that, while previous observations of oceanic marine snow properties may be applicable to stratified shelf waters, they are not applicable to mixed shelf waters. Moreover, our Phaeocystis -rich flocs in relatively low concentration coastal waters had properties that were similar to flocs previously observed in much higher concentration estuaries. This implies that a common factor, e.g. turbulence, plays a key role in floc strength in coastal waters and estuaries.

We did not measure turbulence properties during this experiment. We do have turbulent energy dissipation $(\varepsilon)$ data (using a FLY turbulence profiler) over tidal cycles from a site close to Site 4 in Liverpool Bay, with similar water depths and tidal characteristics (e.g. same peak current velocity). These data show nearbed spring tide values of $\varepsilon$ varying between ca. $10^{0} \mathrm{~cm}^{2}$ $\mathrm{s}^{-3}$ at peak flows and $3 \times 10^{-3} \mathrm{~cm}^{2} \mathrm{~s}^{-3}$ at slack waters. Experiments by Alldredge et al. (1990) suggest that many biologically active flocs can resist rupture by fluid shear even at energy dissipation rates of $10^{0} \mathrm{~cm}^{2}$ $\mathrm{s}^{-3}$. This is consistent with our observations: the largest flocs we observed were those resuspended at peak flows and peak energy dissipation rates. Our turbulence data show near-bed values of the Kolmogorov microscale between $300 \mu \mathrm{m}$ at peak spring tide flow and $1200 \mu \mathrm{m}$ at slack water. Our measured near-bed median particle size at Site 4 averaged $250 \mu \mathrm{m}$ at peak flow and $60 \mu \mathrm{m}$ at slack water. Median particle size was generally less than the turbulence microscale throughout the tidal cycle (though sometimes exceeding it at peak flow) and less by a very large margin at slack water. At peak flow, there were obviously particles larger than the median, some exceeding $500 \mu \mathrm{m}$. These values suggest that the size of much of the resuspended material was constrained by microturbulence, but some flocs exceeded the microturbulence scale. At slack water, floc size was much less than the microturbulence scale because the larger flocs had settled to the bed.

Parker et al. (1972) proposed expressions for maximum stable floc diameter $\left(d_{\max }\right)$ for flocs both larger and smaller than the Kolmogorov microscale $(\eta)$. These are of the form $d_{\max }=C \varepsilon^{-\gamma}$, where $C$ is a coefficient of floc strength and $\gamma$ is 1 when flocs are larger than $\eta$ and 0.5 when flocs are smaller than $\eta$. Using our turbulence data, this expression provides values of $C$ that range from 0.003 (slack water) to 0.5 (peak flow) on the assumption of an equilibrium between floc size and fluid shear (though this is not necessarily the case when floc supply and shear vary dramatically on short time scales). This implies much stronger flocs at peak flow than at slack water. Resuspended flocs dominated SPM at peak flow at the coastal sites; smaller flocs in long-term suspension characterised slack water. So resuspended flocs were stronger than flocs in longterm suspension. This distinguishes SPM properties in coastal waters from marine snow properties in open oceanic waters.

We do not know if our observations hold for all algalrich flocs in tidal shelf seas: floc properties surely vary, since different algal functional groups have different morphologies and aggregation mechanisms. Given the impact of biologically mediated aggregation on SPM properties, it is important that such variability of floc properties in shelf seas be quantified before ecological models are used to simulate the drawdown of organic carbon. Furthermore, we need to refine and separate the settling, resuspension and advection pathways that must have contributed to our observation of rapid removal of SPM before we can model rates of drawdown.

Acknowledgements. This work was funded by the Natural Environment Research Council (NERC), UK.

\section{LITERATURE CITED}

Alldredge AL, Silver MW (1988) Characteristics, dynamics and significance of marine snow. Prog Oceanogr 20:41-82

Alldredge AL, Granata TC, Gotschalk CC, Dickey TD (1990) The physical strength of marine snow and its implications for particle disaggregation in the ocean. Limnol Oceanogr 35:1415-1428

Biddanda BA, Pomeroy LR (1988) Microbial aggregation and degradation of phytoplankton-derived detritus in seawater. 1. Microbial succession. Mar Ecol Prog Ser 42: $79-88$

Diercks AR, Asper VL (1997) In situ settling speeds of marine snow aggregates below the mixed layer: Black Sea and Gulf of Mexico. Deep-Sea Res Part I 44:385-398

Eisma D, Li A (1993) Changes in suspended-matter floc size during the tidal cycle in the Dollard estuary. Neth J Sea Res 31:107-117

Gowen RJ, Mills DK,Trimmer M, Nedwell DB (2000) Production and its fate in two coastal regions of the Irish Sea: the influence of anthropogenic nutrients. Mar Ecol Prog Ser 208:51-64

Gustafsson AÖ, Gschwend P (1997) Aquatic colloids: concepts, definitions and current challenges. Limnol Oceanogr 42:519-528

Hansen JLS, Kiorboe T, Alldredge AL (1996) Marine snow derived from abandoned larvacean houses: sinking rates, particle content and mechanisms of aggregate formation. Mar Ecol Prog Ser 141:205-215

Hill PS (1998) Controls on floc size in the sea. Oceanography 11:13-18

Jago CF, Jones SE (1998) Observation and modelling of the dynamics of benthic fluff resuspended from a sandy bed in the southern North Sea. Cont Shelf Res 18:1255-1282

Jago CF, Bull CF (2000) Quantification of errors in transmissometer-derived concentration of suspended particulate matter in the coastal zone: implications for flux determinations. Mar Geol 169:273-286

Jago CF, Bale AJ, Green MO, Howarth MJ and 6 others (1993) Resuspension processes and seston dynamics. Philos Trans R Soc Lond A 343:475-491 
Jago CF, Jones SE, Latter RJ, McCandliss RR, Hearn MR, Howarth MJ (2002) Resuspension of benthic fluff by tidal currents in deep stratified waters, northern North Sea. J Sea Res 48:259-269

Jago CF, Jones SE, Sykes P, Rippeth T (2006) Temporal variation of suspended particulate matter and turbulence in a high energy, tide-stirred, coastal sea: relative contributions of resuspension and disaggregation. Cont Shelf Res 26:2019-2028

Janse I, van Rijssel M, Gottschal JC, Lancelot C, Gieskes WWC (1996) Carbohydrates in the North Sea during spring blooms of Phaeocystis: a specific fingerprint. Aquat Microb Ecol 10:97-103

Jones SE, Jago CF (1996) Measurement of particle settling velocity using quasi in situ settling velocity tubes. J Sea Res 36:6367

Jones SE, Jago CF, Bale AJ, Chapman D, Howland R, Jackson J (1998) Aggregation and resuspension of suspended particulate matter at a seasonally stratified site in the southern North Sea: physical and biological controls. Cont Shelf Res 18:12831310

Kerherve P, Charriere B, Gadel F (1995) Determination of marine monosaccharides by high-pH anion-exchange chromatography with pulsed amperometric detection. J Chromatogr A 718:283-289

Kiørboe T, Anderson KP, Dam HG (1990) Coagulation efficiency and aggregate formation in marine phytoplankton. Mar Biol 107:235-245

Lampitt RS, Hillier WR, Challenor PG (1993) Seasonal and diel variation in the open ocean concentration of marine snow aggregates. Nature 362:737-739

Lancelot C, Wassman P, Barth H (1994) Ecology of Phaeocystis-dominated ecosystems. J Mar Syst 5:1-4

Law DJ, Bale AJ, Jones SE (1997) Adaptation of focused beam reflectance measurement to in-situ particle sizing in estuaries and coastal waters. Mar Geol 140:47-59

Leppard GG (1995) The characterisation of algal and microbial mucilages and their aggregates in aquatic ecosystems. Sci Total Environ 165:103-131

Lochte K, Turley CM (1988) Bacteria and cyanobacteria associated with phytodetritusin the deep sea. Nature 333: 67-69

Osinga R, Kwint RLJ, Lewis WE, Kraay GW, Lont JD, Lindeboom HJ, vanDuyl FC (1996) Production and fate of dimethylsulfide and dimethylsulfoniopropionate in pelagic microcosms: the role of sedimentation. Mar Ecol Prog Ser 131:275-286

Editorial responsibility: Howard Browman (Associate Editorin-Chief), Storebø, Norway
Parker DS, Kaufman WJ, Jenkins D (1972) Floc breakup in turbulent flocculation processes. J Sanit Eng Div Proc Am Soc Civ Eng 98:79-99

Passow U, Alldredge AL (1994) Distribution, size and bacterial colonisation of transparent exopolymeric particles (TEP) in the ocean. Mar Ecol Prog Ser 113:185-198

Passow U, Wassman P (1994) On the trophic fate of Phaeocystis pouchetii (Hariot). IV. The formation of marine snow by P. pouchetii. Mar Ecol Prog Ser 104:153-161

Passow U, Shipe RF, Murray A, Pak DK, Brezezinski MA, Alldredge AL (2001) The origin of transparent exopolymer particles (TEP) and their role in the sedimentation of particulate matter. Cont Shelf Res 21:327-346

Pilskaln CH, Lehmann C, Paduan JB, Silver MW (1998) Spatial and temporal dynamics in marine aggregate abundance, sinking rate and flux: Monterey Bay, central California. Deep-Sea Res Part II 45:1803-1837

Riebesell U (1991a) Particle aggregation during a diatom bloom. 1. Physical aspects. Mar Ecol Prog Ser 69:273-280

Riebesell U (1991b) Particle aggregation during a diatom bloom. 2. Biological aspects. Mar Ecol Prog Ser 69: 281-282

Riebesell U (1993) Aggregation of Phaeocystis during phytoplankton spring blooms in the southern North Sea. Mar Ecol Prog Ser 96:281-289

Riebesell U, Reigstad M, Wassman P, Noji T, Passow U (1995) On the trophic fate of Phaeocystis pouchetii (Hariot). 6. Significance of Phaeocystis-derived mucus for vertical flux. Neth J Sea Res 33:193-203

Shanks AL (2002) The abundance, vertical flux, and stillwater and apparent sinking rates of marine snow in a shallow coastal water column. Cont Shelf Res 22:2045-2064

Smetacek VS (1985) Role of sinking in diatom life history cycles: ecological, evolutionary and geological significance. Mar Biol 84:239-251

Tett P, Joint I, Purdie D, Baars M and 8 others (1993) Biological consequences of tidal stirring gradients in the North Sea. Philos Trans R Soc Lond A 340:493-508

Thomas H, Bozac Y, Elkalay K, Baar HJW (2004) Enhanced open ocean storage of $\mathrm{CO}_{2}$ from shelf sea pumping. Science 304:1005-1008

Weiss T, Tande K, Verity P, Hansen F, Geiskes W (1994) The trophic significance of Phaeocystis blooms. J Mar Syst 5: $67-79$

Winterwerp JC (1998) A simple model for turbulence induced flocculation of cohesive sediment. J Hydraul Res 36: 309-332

Submitted: December 4, 2006; Accepted: March 31, 2007

Proofs received from author(s): August 30, 2007 